\title{
Impeachment de Dilma Rousseff: estratégias argumentativas em editoriais do jornal O Globo
}

\author{
Dilma Rousseff's Impeachment: Argumentative Strategies in O Globo \\ Newspaper Editorials
}

\section{Maria Eduarda Giering* (iD)}

eduardag@unisinos.br

https://orcid.org/0000-0001-8098-4238

\author{
Júlia Klein Caldas** (D) \\ juliaklek@gmail.com \\ https://orcid.org/0000-0002-4057-3802
}

\section{Resumo}

Esta pesquisa analisa estratégias argumentativas utilizadas nos editoriais do jornal O Globo, "Reformar a Previdência seria bom começo de Temer" e "Otimismo com o novo tom do Planalto", veiculados durante o processo de impeachment de Dilma Rousseff. Nosso objetivo é identificar como os editoriais constroem os personagens envolvidos no processo e como a mídia pode influenciar a opinião pública. A metodologia considera a situação de comunicação em que se inserem os editoriais, os procedimentos da construção enunciativa e os elementos de base da relação argumentativa. Como conclusão, identificaram-se, nos editoriais analisados, o engajamento do locutor na defesa de uma tese favorável à destituição da então presidenta Dilma e a expressão da Opinião, que desqualifica o lulismo e o PT, por meio da modalidade delocutiva.

Palavras-chave: Discurso midiático; Representação; Argumentação; Lógica argumentativa; Construção de sentido.

\section{Abstract}

This research analyzes argumentative strategies used in the editorials of the newspaper $O$ Globo, "Reforming Social Security would be a good start for Temer" and "Optimism with the new tone of the Planalto", published during Dilma Rousseff's impeachment process. Our goal is to identify how editorials build the characters involved in the process and how

* Professora Doutora na Universidade do Vale do Rio dos Sinos - Unisinos, Programa de Pós-Graduação em Linguística Aplicada, São Leopoldo, RS, Brasil.

** Jornalista, mestra e doutoranda na Universidade do Vale do Rio dos Sinos - Unisinos, Programa de PósGraduação em Linguística Aplicada, São Leopoldo, RS, Brasil.

\section{LINHA D'ÁGUA}


media can influence public opinion. The methodology considers the communication situation in which the editorials are inserted, the procedures of the enunciative construction and the basic elements of the argumentative relationship. As a conclusion, it was identified, in the editorials analyzed, the engagement of the speaker in the defense of a favorable thesis towards the dismissal of President Dilma and the expression of the Opinion, that disqualifies Lulism and PT, through the delocative modality.

Keywords: Media discourse; Representation; Argumentation; Argumentative logic; Meaning construction.

\section{Introdução}

O campo jornalístico tem a informação como principal elemento, mas ao utilizar a linguagem para elucidar os fatos relevantes à sociedade, os veículos de comunicação constroem enunciados de acordo com sua linha editorial, considerando os interesses econômicos, políticos e sociais da organização. Desse modo, não é possível seguir o velho conceito de que as empresas de mídia são isentas e apartidárias. Um exemplo disso ocorre com a escolha de determinadas fontes para compor notícias e reportagens, além do léxico utilizado nos textos. Mas, enquanto esses gêneros apenas sugerem um direcionamento, o editorial manifesta claramente a opinião da empresa. Com uma visada de fazer-crer, o editorialista compartilha o universo de crenças do veículo de comunicação com o público, com o objetivo de persuadir os interlocutores e construir sentidos.

O jornal $O$ Globo, que pertence às Organizações Globo, é o segundo periódico de maior circulação no país ${ }^{1}$, com uma média de 270 mil exemplares impressos nos dias úteis e 350 mil aos domingos, dia de maior distribuição. De acordo com a própria empresa, o alcance do grupo ultrapassa 100 milhões de brasileiros em suas múltiplas plataformas ${ }^{2}$. Tendo em vista o peso do grupo de mídia em questão e a incessante cobertura em torno da destituição da então presidenta Dilma Rousseff, este estudo identificou os elementos de base da relação argumentativa, estruturada nos editoriais sob os títulos: "Reformar a Previdência seria bom começo de Temer", veiculado pelo jornal O Globo no dia 29 de abril de 2016, e "Otimismo com o novo tom do Planalto", publicado em 13 de maio de 2016, um dia após o afastamento de Rousseff para o julgamento do processo de impeachment.

Seguindo os preceitos da Teoria Semiolinguística do Discurso, de Patrick Charaudeau (1992; 2008), identificaram-se estratégias discursivas utilizadas pelo jornal para a construção da imagem das principais figuras do impeachment, evidenciando como a representação produzida pelas Organizações Globo, por intermédio da construção enunciativa e da

1 De acordo com a pesquisa Mídia Dados 2018. Disponível em: https://www.gm.org.br/midia-dados-2018. Acesso em: 02 out. 2020.

2 Globo celebra alcance de mais de 100 milhões de pessoas por dia. Disponível em: https://redeglobo.globo.com/novidades/noticia/globo-celebra-alcance-de-mais-de-100-milhoes-de-pessoaspor-dia.ghtml_Acesso em: 02 out. 2020.

\section{LINHA D'́GUA}


organização argumentativa (CHARAUDEAU, 1992), influenciou a opinião pública durante o processo de impeachment.

Assim que Michel Temer assumiu o Palácio do Planalto como presidente interino, passou a ganhar destaque nos meios de comunicação, em especial nos veículos das Organizações Globo. Como a mídia mobiliza o público com a difusão ou o encerramento de discussões, em especial ao abordar temas relevantes para o país, é de fundamental importância compreendermos o papel da empresa líder na legitimação do impeachment e na crise de legitimidade do governo Temer.

\section{0 discurso midiático}

Segundo Charaudeau (2010), o locutor atribui sentidos explícitos ou implícitos ao construir seus enunciados, conforme suas condições de produção e as projeções que faz sobre seu interlocutor. Em vista disso, o linguista propõe ao analista que construa a situação de comunicação na qual ocorre a interação, ou seja, os dados externos à linguagem que formam um conjunto de condições não enunciadas (CHARAUDEAU, 2015), as quais estabelecem algumas condições para a determinação do sentido. O linguista denomina de "contrato" (CHARAUDEAU, 2008) o quadro ao qual se reportam os indivíduos de uma comunidade social quando iniciam uma troca de linguagem.

Para isso, segundo ele, é necessário considerar: quem são os sujeitos da interação, avaliando a identidade psicossocial dos participantes; qual a temática em questão; com que finalidade se dá a troca; e em que circunstâncias materiais se desenvolve a interação.

O domínio midiático é, para o linguista, um domínio da prática, isto é, o local em que se produzem as interações sociais, definidas por um conjunto de ações, em que o locutor modaliza a sua construção discursiva de acordo com a finalidade institucional de cada organização. Os meios de comunicação possuem credibilidade para falar, uma espécie de poder sob os demais, já que os fatos são apresentados como uma verdade estabelecida. Para Charaudeau (2015, p. 63), “[...] a verdade não está no discurso, mas somente no efeito que produz". Como as grandes empresas de mídia concentram o domínio da informação, elas também "detém uma parte do poder social" (CHARAUDEAU, 2015, p. 63). Dessa forma, o domínio da emissão da informação tende a confundir a opinião pública, aumentando o poder de barganha e a pressão dos conglomerados mídia.

A imprensa é projetada pelos meios de comunicação de massa como relatora da verdade, aquela que está em contato com os fatos. Em relação à credibilidade atribuída ao discurso midiático, as empresas de mídia apresentam uma condição de fazer-crer, na qual detêm o direito à palavra, independentemente da verdade em si. No entanto, a construção do saber passa por um processo complexo, que depende da escolha discursiva de quem informa - pode ser voltada para o mundo (categorias de conhecimento) ou voltada para si (categorias de crença). Aplicada

\section{LINHA D'́GUA}


a contextos sociais distintos, a informação midiática passa por inúmeras instâncias de produção, desde a seleção da pauta até a edição. Nessa perspectiva, segundo Charaudeau (2015), todos os envolvidos colaboram para a produção de uma enunciação aparentemente homogênea, seguindo os preceitos da direção da empresa. Trata-se de "uma coenunciação, [...] um projeto comum a esses atores e do qual se pode dizer que, por ser assumida por esses atores, representa a ideologia do organismo de informação" (CHARAUDEAU, 2015, p. 73). Ao escolher determinadas palavras ou expressões, a mídia pode direcionar determinados valores. Desse modo, enunciados aparentemente neutros revelam o conjunto de crenças de quem os escreve. Ao considerar a informação como discurso, podemos observá-la como resultado de uma combinação de situações que visa a produzir sentido.

\section{A situação de comunicação dos editoriais do jornal O Globo}

Charaudeau (2008) relaciona o ato de linguagem com o contexto psicossocial no qual ele ocorre, considerando os diferentes papéis sociais dos sujeitos participantes do ato de comunicação, bem como as condições de produção e interpretação da linguagem. Dessa forma, a Teoria Semiolinguística do Discurso (TSD) compreende o ato de linguagem como uma troca entre os seres de fala, em uma situação de comunicação concreta, em que o locutor e interlocutor atribuem uma intencionalidade à comunicação, fazendo uso de certas categorias de língua para construir sentido e influenciar o outro. Portanto, a TSD considera o discurso como uma prática social estabelecida em uma mesma situação de comunicação, tendo em vista as condições em que o ato de linguagem foi produzido. Em relação ao processo de comunicação, Gouvêa, Pauliukonis e Monnerat $(2013, \mathrm{n} / \mathrm{p})$ afirmam que “[...] para que o fenômeno comunicativo se realize, o locutor mobiliza o sentido das palavras e suas regras de combinação, numa articulação de sentidos e de formas".

Os editoriais do jornal $O$ Globo pertencem ao domínio midiático e se caracterizam por uma dupla visada: a de demonstração e a de informação. Os parceiros envolvidos no ato de linguagem são o locutor, na figura do editorialista, e os leitores, que representam os interlocutores dessa troca. O propósito dos editoriais é selecionar e comentar um acontecimento político ou social, com uma finalidade discursiva que visa a um fazer-crer. Para analisar os editoriais do domínio midiático, é necessário considerar as condições contratuais em que o ato de comunicação se realiza.

O jornal $O$ Globo se intitula como "o preferido dos formadores de opinião"3 e apresenta maior audiência nas classes B e C (50\% e 28\%, respectivamente), com leitores de faixa etária bem distribuída ( 60 anos ou mais equivalem a 20\%, 30 a 39 anos respondem por $19 \%$ e 20 a 29 anos ocupam 18\%), de acordo com dados apresentados pelo InfoGlobo ${ }^{4}$. O perfil dos leitores

\footnotetext{
3 Dados divulgados pelo InfoGlobo. Disponível em: https://www.infoglobo.com.br/Anuncie/ProdutosDetalhe.aspx?IdProduto=91. Acesso em: 03 out. 2020.

4 Idem 3.
}

\section{LINHA D'́́GUA}


do jornal impresso e do site é semelhante, com predominância dos internautas da classe B (59\%). O site possui 25.360 .822 milhões de visitas ao mês.

Por se tratar de um dos maiores periódicos do país ${ }^{5}$, o jornal $O$ Globo é um veículo bastante procurado por leitores pertencentes a diferentes camadas da sociedade. Entretanto, não se trata de um jornal popular. Em relação à editoria Opinião (como são chamados os editoriais), o jornal não aponta dados de acesso pela audiência. Contudo, considera-se que o público leitor dos editoriais é especializado, diferentemente do que ocorre com os demais cadernos temáticos. Presume-se que, em função da recorrente temática política dos textos opinativos, os editoriais visam, como público-alvo, políticos, grandes empresários e assinantes, já que o gênero editorial retrata o ponto de vista da empresa, levando em conta sua linha editorial e os interesses sociais e políticos de seus controladores.

Conforme a Pesquisa Brasileira de Mídia 2016 - Hábitos de Consumo de Mídia pela População Brasileira ${ }^{6}$, promovida, em 2017, pela Secretaria de Comunicação Social do governo federal, a organização configura o maior conglomerado de comunicação do Brasil, sendo sua emissora de TV a líder em audiência, e o jornal em questão, um dos mais lidos do país, inclusive na versão online.

Sobre os papéis comunicativos desempenhados pelos parceiros da troca em função do contrato de comunicação (CHARAUDEAU, 2008), o editorialista, que representa a opinião da empresa, ocupa uma posição de superioridade e influência sobre os interlocutores, tendo em vista o peso do grupo de mídia em questão. Salientamos que, ao longo de décadas, o fundador Roberto Marinho foi o autor dos editoriais do jornal ${ }^{7}$. Nos dias de hoje, de acordo com os Princípios Editoriais do grupo Globo ${ }^{8}$ (seção II, item 4), o conselho editorial é composto por "membros da família Marinho e jornalistas que dirigem as redações".

$\mathrm{Na}$ Estrutura Corporativa das Organizações Globo 9 (ocupando os mais altos cargos administrativos), estão o presidente, Roberto Irineu Marinho, e os vice-presidentes, João Roberto Marinho (também presidente do Conselho Editorial) e José Roberto Marinho.

Os editoriais evidenciam uma visada de fazer-crer, em que o jornal $O$ Globo assume o papel de detentor da verdade e, ao compartilhar seu sistema de crenças com o público, tenta persuadir o interlocutor, no intuito de esse aderir ao seu discurso.

5 De acordo com a pesquisa Mídia Dados 2018. Disponível em: https://www.gm.org.br/midia-dados-2018 Acesso em: 02 out. 2020.

6 Pesquisa Brasileira de Mídia 2016 - Hábitos de Consumo de Mídia pela População Brasileira. Disponível em: http://www.secom.gov.br/atuacao/pesquisa/lista-de-pesquisas-quantitativas-e-qualitativas-de-contratosatuais/pesquisa-brasileira-de-midia-pbm-2016.pdf/view Acesso em: 03 out. 2020.

7 Editoriais escritos por Roberto Marinho. Memória Roberto Marinho. Opinião. Disponível em: https://robertomarinho.globo.com/opiniao/ Acesso em: 02 out. 2020.

8 Princípios Editoriais do Grupo Globo. Disponível em: https://oglobo.globo.com/principios-editoriais/ Acesso em: 01 out. 2020.

9 Estrutura corporativa do Grupo Globo. Conselho de administração. Disponível em: https://grupoglobo.globo.com/estrutura-corporativa/. Acesso em: 02 out. 2020.

\section{LINHA DÁGUA}




\section{Modos de Organização Enunciativo e Argumentativo do Discurso}

Charaudeau (2008) apresenta os Modos de Organização como procedimentos que permitem utilizar certas categorias de língua, de acordo com a finalidade discursiva do falante no ato de comunicação. Neste artigo, focaremos nos Modos Enunciativo e Argumentativo de Organização do Discurso. Cada Modo possui uma função de base, ou seja, um projeto de fala do locutor e um princípio de organização, que serve para ordenar o mundo referencial construído por ele.

O Modo de Organização Enunciativo do Discurso, de acordo com o autor (2008), focaliza nos protagonistas, que estão situados no espaço interno da fala (considerando a relação de influência, o ponto de vista dos sujeitos e a retomada de algo dito anteriormente). Nesse sentido, Charaudeau (2008) distingue as três funções do Modo Enunciativo: estabelecer uma relação de influência entre locutor e interlocutor, que corresponde ao comportamento alocutivo (quando o sujeito falante impõe um comportamento ao interlocutor); revelar o ponto de vista do locutor, denominado como elocutivo (quando o falante enuncia o seu ponto de vista sobre o mundo, sem que o interlocutor seja envolvido nesse posicionamento); desvincular o locutor e o interlocutor da encenação, o que configura o comportamento delocutivo (o locutor apresenta seu propósito comunicativo como se não fosse responsável por ele, sem considerar o interlocutor diretamente).

Em relação ao Modo de Organização Argumentativo do Discurso, Charaudeau (2008) postula que se trata de uma atividade da linguagem que busca persuadir o outro para influenciálo ou, pelo menos, para orientar o seu pensamento. Segundo o linguista, a argumentação vai além de uma sequência de conectores lógicos, já que, frequentemente, o aspecto argumentativo de um discurso está implícito, isto é, apresentado de maneira indireta.

De acordo com o autor, para que exista argumentação, é necessário que o locutor apresente uma proposta sobre o mundo e provoque um questionamento no outro que, por sua vez, deve desenvolver um raciocínio em relação à proposta (pode aceitar ou refutar).

Charaudeau $(1992 ; 2008)$ apresenta a argumentação como uma atividade discursiva com o objetivo de fazer o outro crer no que é dito. O Modo de Organização Argumentativo permite construir explicações sobre o mundo a partir de duas perspectivas: a demonstrativa e a persuasiva. Na primeira, são estabelecidas relações de causalidade (relações entre asserções), demonstradas por procedimentos que o autor denomina como organização da lógica argumentativa. Já na razão persuasiva, o objetivo é constituir, a partir de argumentos, provas que justifiquem a construção de mundo e as relações de causalidade que unem as asserções.

No âmbito da linguística, a asserção representa o valor modal de um enunciado. Dentro da lógica argumentativa, as asserções representam os elementos de base da relação argumentativa. Segundo Charaudeau (2008, p. 209), essa relação é composta pelos elementos

\section{LINHA DÁGUA}


"asserção de partida", identificada como A1, que representa um dado ou premissa, uma "asserção de chegada", denominada como A2, que representa uma conclusão ou resultado, e uma ou mais "asserções de passagem", que relacionam A1 com A2 e representam o universo de crenças do locutor (apontam para uma conclusão).

Ao compartilhar suas posições acerca do mundo, o locutor deve estabelecer uma prova para validar o argumento apresentado (a alegação de A1 implica a existência de A2), com o objetivo de motivar o interlocutor a aceitar tal posicionamento.

\section{Análise}

No que tange ao gênero editorial, destacamos sua principal característica, que é marcar um posicionamento institucional. Trata-se de uma manifestação formal da empresa jornalística em relação aos principais acontecimentos sociais e políticos do momento. Esse texto, sem assinatura, transmite os valores defendidos pela instituição que o reproduz. Nesse sentido, o sujeito editorialista encena uma representação de mundo a partir de uma realidade comentada. Para Charaudeau (2015, p. 235), o editorial apresenta "[...] um engajamento relativamente livre da instância midiática", uma vez que permite revelar o ponto de vista da empresa em relação a uma questão específica. Nessa perspectiva, o agendamento dos temas e a abordagem discursiva utilizada nos textos irão indicar a linha editorial adotada pela instituição e os interesses políticos e econômicos da organização.

Em função da extensão deste artigo, selecionaram-se dois editoriais do jornal $O$ Globo para análise, ambos veiculados durante o processo de julgamento do impeachment da então presidenta Dilma Rousseff. Os textos estão em ordem cronológica de acontecimento: "Reformar a Previdência seria bom começo de Temer" (publicado em 29/04/2016) e "Otimismo com o novo tom do Planalto" (veiculado em 13/05/2016), conforme as capturas de tela que seguem. A íntegra dos editoriais está disponível para assinantes do jornal, através de pesquisa pelo Acervo Digital O Globo. 
Figura 1. Captura de tela do editorial "Reformar a Previdência seria bom começo de Temer"

\section{Opinião}

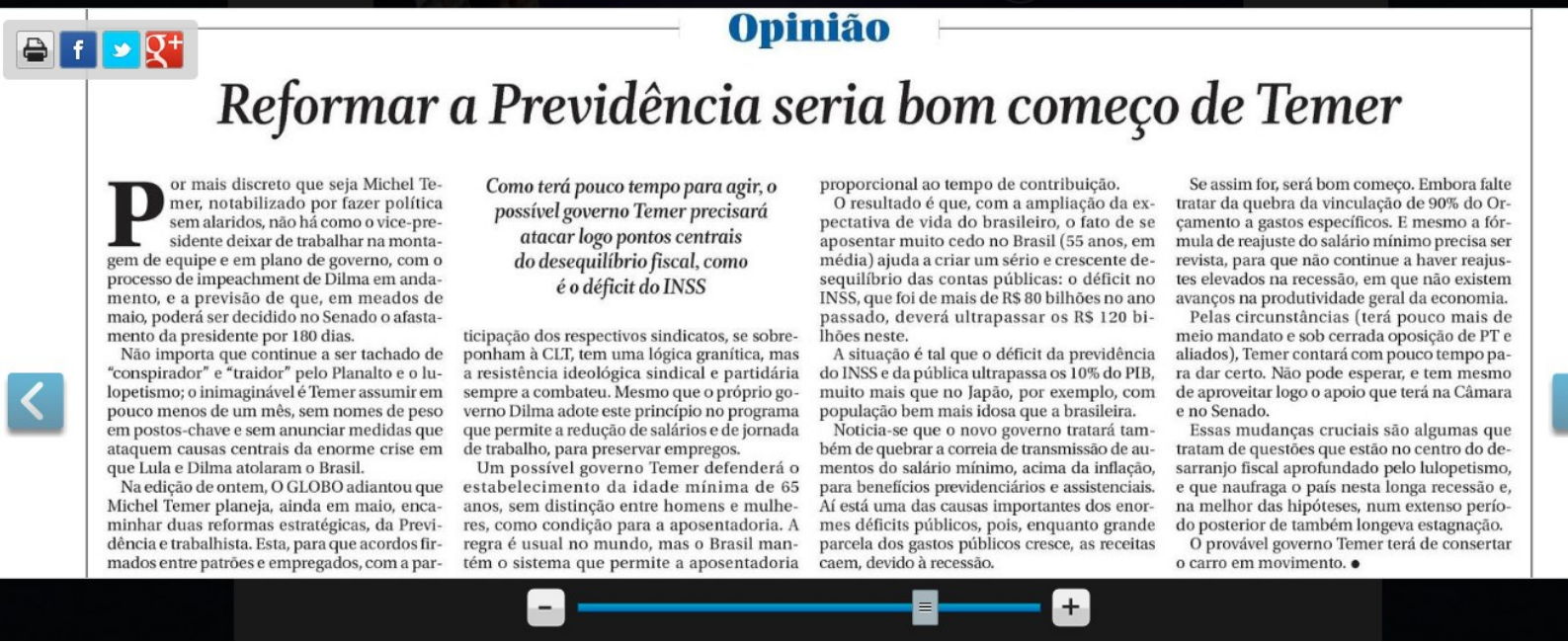

Fonte: Acervo O Globo (2016).

Ressaltamos que, na data de publicação desse editorial, o processo de impeachment já estava em andamento no Senado. Entretanto, Dilma Rousseff ainda ocupava o cargo de presidenta do país (o afastamento de 180 dias para os senadores julgarem o processo ocorreu somente em 12 de maio de 2016).

No que diz respeito aos componentes da lógica argumentativa (CHARAUDEAU, 2008), a asserção de partida (A1), que atribui características aos objetos discursivos, é determinada pela premissa de que a Reforma da Previdência é positiva para o país. O outro elemento que compõe essa lógica é a asserção de chegada (A2), que busca evidenciar a razão de A1. Nesse editorial, A2 é representada pelo locutor com o argumento de que aprovar a Reforma da Previdência seria um bom começo para Temer. Para integralizar essa relação argumentativa, demonstram-se as asserções de passagem, que são os argumentos trazidos pelo locutor para justificar uma relação de causalidade entre A1 e A2.

Para evidenciar a relação argumentativa desse editorial, apresentam-se os Quadros 1 e 2:

Quadro 1. A asserção de partida e a asserção de chegada do editorial "Reformar a Previdência seria bom começo de Temer"

\begin{tabular}{c|c}
$\begin{array}{c}\text { Asserção de partida } \\
\text { (Dado / Premissa / A1) }\end{array}$ & $\begin{array}{c}\text { Asserção de chegada } \\
\text { (Conclusão / A2) }\end{array}$ \\
\hline $\begin{array}{c}\text { As reformas Trabalhista e da Previdência são positivas } \\
\text { para o país. }\end{array}$ & \begin{tabular}{c} 
Reformar a Previdência seria bom começo de Temer. \\
\hline
\end{tabular}
\end{tabular}

Fonte: elaborado pelas autoras. 
Quadro 2. As asserções de passagem do editorial "Reformar a Previdência seria bom começo de Temer"

\section{Asserções de passagem}

\section{Dilma e PT}

Michel Temer

\begin{abstract}
Não importa que continue a ser tachado de "conspirador" e "traidor" pelo Planalto e o lulopetismo; o inimaginável é Temer assumir em pouco menos de um mês sem nomes de peso em postos-chave e sem anunciar medidas que ataquem causas centrais da enorme crise em que Lula e Dilma atolaram o Brasil.

Esta [faz referência à Reforma Trabalhista], para que acordos firmados entre patrões e empregados, com a participação dos respectivos sindicatos, se sobreponham à CLT, tem uma lógica granítica, mas a resistência ideológica sindical e partidária sempre a combateu.
\end{abstract}

Pelas circunstâncias (terá pouco mais de meio mandato e sob cerrada oposição de PT e aliados) [...].

Essas mudanças cruciais são algumas que tratam de questões que estão no centro do desarranjo fiscaI aprofundado pelo lulopetismo, e que naufraga o país nesta longa recessão e, na melhor das hipóteses, num extenso período posterior de também longeva estagnação.
Por mais discreto que seja Michel Temer, notabilizado por fazer política sem alaridos, não há como o vicepresidente deixar de trabalhar na montagem de equipe e em plano de governo, com o processo de impeachment de Dilma em andamento [...]

Na edição de ontem [28/04/2016], O GLOBO adiantou que Michel Temer planeja, ainda em maio, encaminhar duas reformas estratégicas, da Previdência e trabalhista.

Como terá pouco tempo para agir, o possível governo Temer precisará atacar logo pontos centrais do desequilíbrio fiscal, como é o déficit do INSS.

Um possível governo Temer defenderá o estabelecimento da idade mínima de 65 anos, sem distinção entre homens e mulheres, como condição para a aposentadoria.

Noticia-se que o novo governo tratará também de quebrar a correia de transmissão de aumentos do salário mínimo, acima da inflação, para benefícios previdenciários e assistenciais

Se assim for, será bom começo.

[...] Temer contará com pouco tempo para dar certo.

O provável governo Temer terá de consertar o carro em movimento.

Fonte: elaborado pelas autoras.

De acordo com o modelo da lógica argumentativa, o editorial em questão apresenta os objetos discursivos Dilma Rousseff e Partido dos Trabalhadores (PT) como os responsáveis pela crise no Brasil, ao passo que produz uma argumentação favorável à figura de Michel Temer, desde que o então vice-presidente assumisse as reformas defendidas pelo jornal. As asserções de passagem listadas no Quadro 2 revelam a apreciação da empresa em relação à Reforma da Previdência e o posicionamento avesso aos representantes petistas.

Em relação à orientação argumentativa do editorial, já no título, "Reformar a Previdência seria bom começo de Temer", o locutor sugere um comportamento a Michel Temer. O verbo no futuro do pretérito, "seria", modaliza o enunciado e indica, segundo o 
editorialista, uma possível ação a realizar. Trata-se de uma delocução, já que não há a implicação direta dos envolvidos no ato de linguagem.

No trecho "Essas mudanças cruciais são algumas que tratam de questões que estão no centro do desarranjo fiscal aprofundado pelo lulopetismo, e que naufraga o país nesta longa recessão e, na melhor das hipóteses, num extenso período posterior de também longeva estagnação", destacamos a manifestação do ponto de vista do locutor de acordo com o seu universo de crenças, ou seja, apresenta-se a modalidade da Opinião, expressa por meio de uma Asserção. O uso de termos como "desarranjo fiscal" e "naufraga" demonstra uma construção negativa da imagem do PT e de seus aliados.

Ao longo do editorial, o locutor modaliza seu discurso para exaltar um possível novo governo dirigido por Michel Temer, ao passo que desqualifica a gestão petista, proclamando a sua aversão ao partido e àquilo que o PT representa.

Figura 2. Captura de tela do editorial "Otimismo com o novo tom do Planalto"

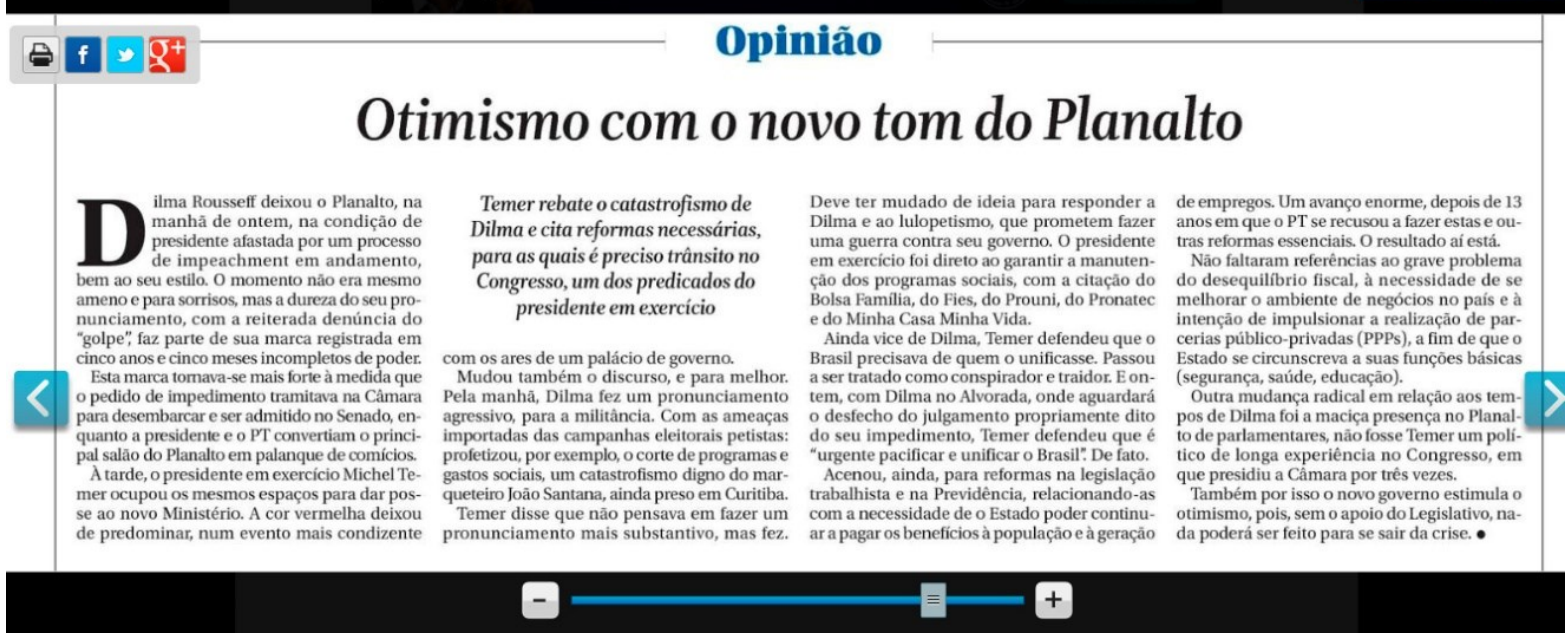

Fonte: Acervo O Globo (2016).

Destacamos que esse editorial foi veiculado um dia após o afastamento da então presidenta Dilma para o julgamento do processo de impeachment, ocorrido em 12 de maio de 2016. No mesmo dia, Michel Temer assumiu a presidência do país como interino.

De acordo com os componentes da lógica argumentativa (CHARAUDEAU, 1992; 2008), a asserção de partida (A1), que atribui características aos seres e descreve suas ações ou feitos, é expressa, nesse editorial, a partir da premissa de que houve uma mudança no Palácio do Planalto com o afastamento de Dilma Rousseff e a posse interina de Michel Temer.

Já a asserção de chegada (A2), que representa a causa ou consequência de A1, é manifestada pelo argumento de que o tom do novo governo de Michel Temer estimula o otimismo. Essa asserção demonstra a conclusão ou a legitimidade do argumento defendido pelo

\section{LINHA D'́GUA}


locutor. Para complementar a relação argumentativa desse editorial, apresentam-se as asserções de passagem, que representam o universo de crenças de quem se enuncia. Tais crenças são compartilhadas com os interlocutores, a fim de comprovar uma relação de causalidade entre A1 e A2.

Para explicitar a relação argumentativa do editorial analisado, apresentam-se os Quadros 3 e 4:

Quadro 3. A asserção de partida e a asserção de chegada do editorial "Otimismo com o novo tom do Planalto"

\begin{tabular}{c|c}
$\begin{array}{c}\text { Asserção de partida } \\
\text { (Dado / Premissa / A1) }\end{array}$ & $\begin{array}{c}\text { Asserção de chegada } \\
\text { (Conclusão / A2) }\end{array}$ \\
\hline Otimismo com o novo tom do planalto. & O novo governo Temer estimula o otimismo.
\end{tabular}

Fonte: elaborado pelas autoras.

Quadro 4. As asserções de passagem do editorial "Otimismo com o novo tom do Planalto"

\section{Asserções de passagem}

\section{Dilma e PT}

Dilma Rousseff deixou o Planalto, na manhã de ontem, na condição de presidente afastada por um processo de impeachment em andamento, bem ao seu estilo.

O momento não era mesmo ameno e para sorrisos, mas a dureza do seu pronunciamento, com a reiterada denúncia do 'golpe', faz parte de sua marca registrada em cinco anos e cinco meses incompletos de poder.

Esta marca tornava-se mais forte à medida que o pedido de impedimento tramitava na Câmara para desembarcar e ser admitido no Senado, enquanto a presidente e o PT convertiam o principal salão do Planalto em palanque de comícios”.

Pela manhã, Dilma fez um pronunciamento agressivo, para a militância.

Com as ameaças importadas das campanhas eleitorais petistas: profetizou, por exemplo, o corte de programas e gastos sociais, um catastrofismo digno do marqueteiro João Santana, ainda preso em Curitiba.

\section{Michel Temer}

A tarde, o presidente em exercício Michel Temer ocupou os mesmos espaços para dar posse ao novo Ministério.

A cor vermelha deixou de predominar, num evento mais condizente com os ares de um palácio de governo.

Temer rebate o catastrofismo de Dilma e cita reformas necessárias, para as quais é preciso trânsito no Congresso, um dos predicados do presidente em exercício.

Mudou também o discurso, e para melhor.

Temer disse que não pensava em fazer um pronunciamento mais substantivo, mas fez.

Deve ter mudado de ideia para responder a Dilma e ao lulopetismo, que prometem fazer uma guerra contra o seu governo.

O presidente em exercício foi direto ao garantir a manutenção dos programas sociais, com a citação do Bolsa Família, do Fies, do Prouni, do Pronatec e do Minha Casa Minha Vida.

\section{LINHA DÁGUA}




\begin{abstract}
Ainda vice de Dilma, Temer defendeu que o Brasil precisava de quem o unificasse.

Passou a ser tratado como conspirador e traidor.

E ontem, com Dilma no Alvorada, onde aguardará o desfecho do julgamento propriamente dito do seu impedimento, Temer defendeu que é "urgente pacificar e unificar o Brasil”.

Acenou, ainda, para reformas na legislação trabalhista e na Previdência, relacionando-as com a necessidade de o Estado poder continuar a pagar os benefícios à população e à geração de empregos.

Um avanço enorme, depois de 13 anos em que o PT se recusou a fazer estas e outras reformas essenciais.

Não faltaram referências ao grave problema do desequilíbrio fiscal, à necessidade de se melhorar o ambiente de negócios no país e à intenção de impulsionar a realização de parcerias público-privadas (PPPs), a fim de que o Estado se circunscreva a suas funções básicas (segurança, saúde, educação).

Outra mudança radical em relação aos tempos de Dilma foi a maciça presença no Planalto de parlamentares, não fosse Temer um político de longa experiência no Congresso, em que presidiu a Câmara por três vezes.

Também por isso o novo governo estimula o otimismo, pois, sem o apoio do Legislativo, nada poderá ser feito para sair da crise.
\end{abstract}

Fonte: elaborado pelas autoras.

De acordo com os componentes da lógica argumentativa, o editorial indica uma construção positiva da imagem de Michel Temer, ao mesmo tempo em que desconstrói a figura de Dilma Rousseff, conforme os diferentes argumentos listados no Quadro 4. As asserções de passagem evidenciam, de forma explícita, a tese defendida pelo editorialista, para demonstrar que a posse interina de Michel Temer trouxe otimismo para o país. Por meio do discurso, o locutor emprega argumentos para fundamentar a sua proposta de mundo, expressando o ponto de vista de quem escreve.

No que diz respeito à estrutura argumentativa do editorial, o trecho a seguir caracteriza a ex-presidenta e sua saída do governo federal: "Dilma Rousseff deixou o Planalto, na manhã de ontem, na condição de presidente afastada por um processo de impeachment em andamento, bem ao seu estilo". Aqui o editorialista não explicita como é Dilma Rousseff, mas evoca o conhecimento de mundo dos interlocutores a respeito da então presidenta, por intermédio de uma inferência. O locutor associa Dilma com o momento tenso que vivia, conforme o trecho: "O momento não era mesmo ameno e para sorrisos, mas a dureza do seu pronunciamento, com a reiterada denúncia do 'golpe', faz parte de sua marca registrada em cinco anos e cinco meses incompletos de poder". Ao afirmar que ela deixou o governo "bem ao seu estilo" e que "o 
momento não era ameno e para sorrisos", o editorialista sugere, inicialmente, que, devido ao processo de impeachment, Rousseff se mostrava rígida e sisuda. Entretanto, após o articulador "mas", o locutor destaca o que seria uma característica permanente de Dilma, "sua marca registrada" e "seu estilo": não ser amena nem sorrir. A então presidenta Dilma é construída, assim, definitivamente, como dura e fechada, pois assim teria se mostrado durante todo o período em que governou, ou seja, não se trata de uma característica temporária. Destacamos, também, a opção do locutor em utilizar aspas na palavra "golpe" para manifestar ironia e, assim, evidenciar sua posição contrária ao uso do termo.

A modalidade Opinião está marcada em "Pela manhã, Dilma fez um pronunciamento agressivo, para a militância", na qual o locutor qualifica o pronunciamento da ex-presidenta como agressivo e voltado somente a filiados e eleitores do partido. No trecho "Com as ameaças importadas das campanhas eleitorais petistas: profetizou, por exemplo, o corte de programas e gastos sociais, um catastrofismo digno do marqueteiro João Santana, ainda preso em Curitiba", o locutor deprecia o pronunciamento de Dilma, qualificando-o como um discurso ameaçador, proveniente das campanhas eleitorais petistas, como se a ameaça fosse característica permanente nas campanhas do partido. O verbo "profetizou" aponta para um tom pejorativo do locutor em relação à figura da então presidenta. Nesse segmento, verifica-se um forte posicionamento contrário à Dilma Rousseff e ao PT, com a manifestação da Opinião do editorialista por meio da delocução.

No decorrer do editorial, o locutor aclama o novo governo de Michel Temer, ao mesmo tempo em que desqualifica a gestão de Dilma Rousseff e do PT, caracterizando negativamente esse grupo social.

\section{Conclusão}

Os editoriais jornalísticos seguem os temas em voga na sociedade, principalmente, os relacionados à política. Ao acompanhar o processo político do momento e se posicionar diante dos acontecimentos, o editorialista assume a função de reproduzir oficialmente o ponto de vista da empresa, revelando uma visada de fazer-crer, em que o locutor busca persuadir os leitores para convencer pelo discurso. Para alcançar a proposta deste trabalho, analisamos dois editoriais do jornal $O$ Globo, veiculados durante o processo de impeachment da então presidenta Dilma Rousseff: "Reformar a Previdência seria bom começo de Temer" e "Otimismo com o novo tom do Planalto".

Com base nessa análise, concluímos que os editoriais apresentaram uma reconstrução de fatos políticos, de acordo com o ponto de vista e o posicionamento ideológico das Organizações Globo. A partir da opinião institucional, os editoriais do Globo se valem do poder que o conglomerado de mídia possui e do peso que esses textos apresentam na formação da opinião pública. Os argumentos utilizados pelos editorialistas sobre a destituição da então

\section{LINHA D'́GUA}


presidenta Dilma manifestaram a necessidade do impeachment como uma verdade já estabelecida, reforçada pela defesa da tese apresentada.

$\mathrm{Na}$ encenação do ato de linguagem, constatou-se que o enunciador se apresenta por meio de um comportamento delocutivo, em que impõe aos interlocutores uma representação de mundo seguindo os interesses políticos da empresa. As análises demonstraram inúmeras ocorrências da modalidade Opinião, expressa, nesse caso, pelo modo delocutivo via Asserção, revelando o ponto de vista do editorialista contrário à Dilma Rousseff e ao PT e favorável ao impeachment e à posse de Michel Temer.

$\mathrm{O}$ artigo procurou evidenciar a utilização de estratégias linguístico-discursivas para captar o público leitor e convencê-lo, por meio de um discurso "anti-petista", de que Dilma Rousseff e o lulismo foram os responsáveis pela crise econômica do país e de que, portanto, o impeachment traria benefícios ao Brasil. Ao mesmo tempo, construiu-se uma representação positiva da imagem de Michel Temer, exaltando o ex-mandatário. Trata-se da expressão de opiniões e julgamentos por parte do conglomerado de mídia, que produziu seu discurso para influenciar o leitor na deslegitimação dos representantes petistas e do partido (PT).

\section{Referências}

CHARAUDEAU, Patrick. Grammaire du sens et de l'expression. Paris: Hachette, 1992.

CHARAUDEAU, Patrick. Linguagem e discurso: modos de organização. São Paulo: Contexto, 2008.

CHARAUDEAU, Patrick. Um modelo sócio-comunicacional do discurso: entre situação de comunicação e estratégias de individualização. [não paginado], 2010. Disponível em: http://www.patrick-charaudeau.com/Um-modelo-socio-comunicacional-do.html. Acesso em: 02 out. 2020.

CHARAUDEAU, Patrick. Discurso das Mídias. São Paulo: Contexto, 2015.

Globo.com. GLOBO celebra alcance de mais de 100 milhões de pessoas por dia. 23 de outubro de 2017. Disponível em: https://redeglobo.globo.com/novidades/noticia/globo-celebraalcance-de-mais-de-100-milhoes-de-pessoas-por-dia.ghtml. Acesso em: 02 out. 2020.

Globo.com. Memória Roberto Marinho. Opinião. Disponível em: https://robertomarinho.globo.com/opiniao/. Acesso em: 01 out. 2020.

GOUVÊA, L. H. M.; PAULIUKONIS, M. A. L.; MONNERAT, R. S. M. Modalização em textos midiáticos: estratégias de construção de sentido. Revista Latinoamericana de Estudios del Discurso [não paginado]. Disponível em: https://raled.comunidadaled.org/index.php/raled/article/view/52/54. Acesso em: 01 out. 2020.

Grupo Globo. Estrutura corporativa do Grupo Globo. Conselho de administração. Disponível em: https://grupoglobo.globo.com/estrutura-corporativa/. Acesso em: 02 out. 2020.

InfoGlobo. Hábitos de Consumo dos Leitores. Disponível em: https://www.infoglobo.com.br/Anuncie/ProdutosDetalhe.aspx?IdProduto=91. Acesso em: 03 out. 2020.

\section{LINHA DÁGUA}


Gm.org.br. Midia Dados 2018. Disponível em: <https://www.gm.org.br/midia-dados-2018>. Acesso em: 02 out. 2020.

O Globo. Opinião. Disponível em: https://oglobo.globo.com/opiniao/. Acesso em: 02 out. 2020.

O Globo. Princípios Editoriais do Grupo Globo. Disponível em: https://oglobo.globo.com/principios-editoriais/. Acesso em: 01 out. 2020.

PRESIDÊNCIA DA REPÚBLICA. Pesquisa Brasileira de Mídia 2016 - Hábitos de Consumo de Mídia pela População Brasileira. Disponível em: http://www.secom.gov.br/atuacao/pesquisa/lista-de-pesquisas-quantitativas-e-qualitativas-decontratos-atuais/pesquisa-brasileira-de-midia-pbm-2016.pdf/view. Acesso em: 03 out. 2020.

Recebido: 17/11/2020.

Aprovado: 05/01/2021. 